\title{
Article
}

\section{Tavarua Deoxyriboside A and Jasplakinolide as Potential Neuroprotective Agents: Effects on Cellular Models of Oxidative Stress and Neuroinflammation}

\author{
Alvariño, Rebeca, Alonso, Eva, Tabudravu, Jioji, Pérez-Fuentes, \\ Nadia, Alfonso, Amparo and Botana, Luis M. \\ Available at https://clok.uclan.ac.uk/36230/ \\ Alvariño, Rebeca, Alonso, Eva, Tabudravu, Jioji orcid iconORCID: 0000-0002- \\ 6930-6572, Pérez-Fuentes, Nadia, Alfonso, Amparo and Botana, Luis M. (2021) \\ Tavarua Deoxyriboside $A$ and Jasplakinolide as Potential Neuroprotective \\ Agents: Effects on Cellular Models of Oxidative Stress and Neuroinflammation. \\ ACS Chemical Neuroscience, 12 (1). pp. 150-162. ISSN 1948-7193
}

It is advisable to refer to the publisher's version if you intend to cite from the work. http://dx.doi.org/10.1021/acschemneuro.0c00626

For more information about UCLan's research in this area go to http://www.uclan.ac.uk/researchgroups/ and search for <name of research Group>.

For information about Research generally at UCLan please go to http://www.uclan.ac.uk/research/

All outputs in CLoK are protected by Intellectual Property Rights law, including Copyright law. Copyright, IPR and Moral Rights for the works on this site are retained by the individual authors and/or other copyright owners. Terms and conditions for use of this material are defined in the policies page. 


\title{
Tavarua Deoxyriboside A and Jasplakinolide as Potential Neuroprotective Agents: Effects on Cellular Models of Oxidative Stress and Neuroinflammation
}

\author{
Rebeca Alvariño $^{1}$, Eva Alonso ${ }^{1,2}$, Jioji N. Tabudravu ${ }^{3,4}$, Nadia Pérez-Fuentes ${ }^{1}$, Amparo \\ Alfonso $^{1}$, Luis M. Botana ${ }^{*}$ \\ ${ }^{1}$ Departamento de Farmacología, Facultad de Veterinaria, Universidad de Santiago de \\ Compostela, Lugo 27002, Spain \\ ${ }^{2}$ Fundación Instituto de Investigación Sanitario Santiago de Compostela (FIDIS), Hospital \\ Universitario Lucus Augusti, Lugo 27002, Spain \\ ${ }^{3}$ School of Natural Sciences, Faculty of Science \& Technology, University of Central Lancashire, \\ Preston, Lancashire PR1 2HE, U.K \\ ${ }^{4}$ Marine Biodiscovery Centre, Department of Chemistry, University of Aberdeen, Aberdeen \\ AB24 3UE, Scotland, U.K.
}

\begin{abstract}
The oceans harbour a great reservoir of molecules with unknown bioactivities, which could be useful for the treatment of illnesses that nowadays have no cure, such as neurodegenerative diseases. In this work, we evaluated the neuroprotective potential of the marine Fijian compounds tavarua deoxyriboside $\mathrm{A}$ and jasplakinolide against oxidative stress and neuroinflammation, crucial mechanisms in neurodegeneration. Both metabolites protected SH-SY5Y human neuroblastoma cells from $\mathrm{H}_{2} \mathrm{O}_{2}$ damage, improving mitochondrial function and activating the antioxidant systems of cells. These effects were mediated by their ability of inducing Nrf2 translocation. In BV2 microglial cells activated with lipopolysaccharide, Fijian metabolites also displayed promising results, decreasing the release of pro-inflammatory mediators (ROS, NO, cytokines) through the reduction of gp91 and NFkB-p65 expression. Finally, we performed a coculture among both cell lines, in which treatment with compounds protected SH-SY5Y cells from activated microglia, corroborating their neuroprotective effects. These results
\end{abstract}


suggest that tavarua deoxyriboside $\mathrm{A}$ and jasplakinolide could be used as candidate molecules for further studies against neurodegeneration.

Keywords: oxidative stress, neuroinflammation, gp91, Nrf2, jasplakinolide, tavarua deoxyriboside A

\section{Introduction}

Neurodegenerative diseases constitute an emerging public health issue. Cognitive decline and dementia prevalence are increasing worldwide, and they are projected to continue augmenting due to the aging of developed countries population. Currently, about 50 million people are affected by dementia worldwide. This number is expected to double by 2030 and more than triple by $2050^{1}$. In fact, the World Health Organization has published a global action plan of public health response for 2017-2025, which includes a specific area for dementia as a public health priority focused on diagnosis, treatment, and care of these diseases ${ }^{2}$.

Oxidative stress and mitochondrial dysfunction play a crucial role in neurodegeneration. Neurons are very sensitive to oxidative damage for many reasons, such as their great rate of oxygen consumption and their low amount of antioxidant defences. They have approximately 50 times lower catalase and glutathione (GSH) content compared to other cells ${ }^{3}$. Increasing age leads to an augmentation in the release of reactive oxygen species (ROS), which are mainly produced by mitochondria through the electron transport chain. As mitochondria are great ROS producers, the organelles are also the principal target of oxidative damage ${ }^{4}$. Since mitochondria produce ATP through oxidative phosphorylation, their dysfunction has serious effects on cell viability. High concentrations of ROS can induce the opening of the mitochondrial permeability transition pore, with the resultant 
collapse of the mitochondrial membrane potential $\left(\Delta \Psi_{\mathrm{m}}\right)$ and the rupture of the organelle, which can finally lead to cell death ${ }^{5}$.

ROS accumulation is also involved in neuroinflammation, since these toxic species can induce the activation and proliferation of microglial cells. Furthermore, microglia contribute to oxidative stress by releasing more $\operatorname{ROS}^{6}$. Although the primary objective of these molecules is to kill pathogens, the immune cells of the brain are abnormally activated in neurodegenerative diseases and contribute to their pathogenesis. Along with the production of ROS, microglia releases cytokines such as interleukin-6 (IL-6) or tumor necrosis-alpha (TNF- $\alpha$ ) that are damaging to neurons and can even produce their death ${ }^{7}$. In this context, compounds capable of reducing oxidative stress and neuroinflammation have emerged as a promising therapeutic strategy to counteract neurodegenerative pathologies that nowadays have no cure, such as Parkinson's disease (PD) and Alzheimer's disease $(\mathrm{AD})^{4,8}$. In particular, the oceans harbour an exceptional pool of molecules with a great structural diversity and unknown biological activities, so the research conducted through the elucidation of their mechanisms of action could be helpful for therapeutic approaches directed to these pathologies ${ }^{9}$.

The Fiji Islands, in the South Pacific, possess a great marine biodiversity. More than 400 compounds have been isolated from Fijian organisms, being sponges, ascidians and soft corals the major sources of bioactive products ${ }^{10}$. In this study, the neuroprotective abilities of tavarua deoxyriboside A and jasplakinolide (Figure 1), obtained from Fijian organisms, have been evaluated. The first one was obtained from a tunicate ${ }^{11}$, whilst the cyclic depsipeptide jasplakinolide (also named jaspamide) was isolated from the sponge Jaspis splendens ${ }^{12}$. The biological activity of tavarua deoxyriboside A remains unknown, as it has not been tested so far, whereas jasplakinolide has shown anticancer activity through the promotion of actin polymerization ${ }^{13}$. We have determined their 
neuroprotective potential in two in vitro models of oxidative stress and neuroinflammation with SH-SY5Y human neuroblastoma cells and BV2 murine microglial cells, respectively.

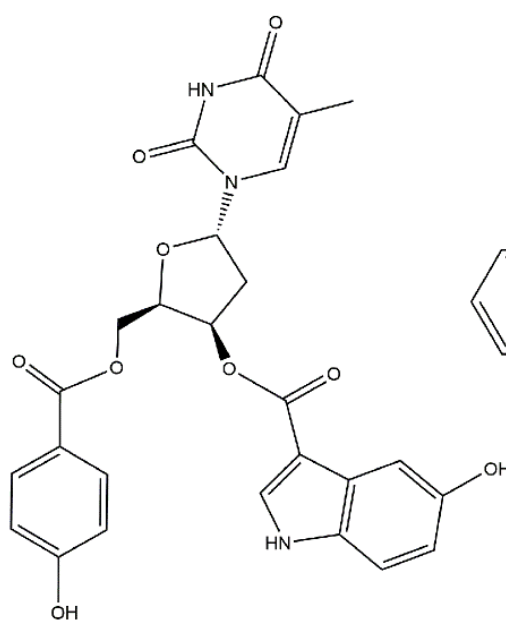

Tavarua deoxyriboside A

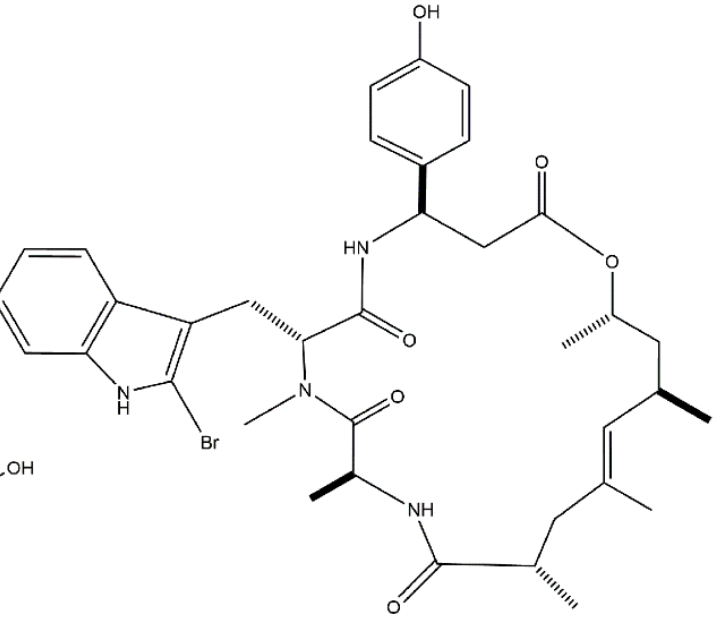

Jasplakinolide

Figure 1. Chemical structures of Fijian compounds

\section{Results}

\subsection{Compounds protect neuronal cells from oxidative stress improving their antioxidant} defences

Before starting oxidative stress experiments, the effects of compounds on neuroblastoma cells viability was tested. With this purpose, SH-SY5Y cells were treated with tavarua deoxyriboside $\mathrm{A}$ and jasplakinolide at concentrations ranging from $0.1 \mathrm{nM}$ to $10 \mu \mathrm{M}$ for $24 \mathrm{~h}$ and MTT test was performed (Figure 2a). Tavarua A did not display significant cytotoxicity at any of the concentrations assayed, although a slight decrease was detected at $10 \mu \mathrm{M}$. As expected, jasplakinolide was significantly toxic at the highest concentrations $(10 \mathrm{nM}-10 \mu \mathrm{M})$. The half maximal inhibitory concentration $\left(\mathrm{IC}_{50}\right)$ of this compound was calculated, obtaining a value of $3.3 \mathrm{nM}\left(95 \%\right.$ confidence interval: 2.2-5.1 nM, $\mathrm{R}^{2}$ : 0.95$)$, 
which is in agreement with previous results in other cell lines ${ }^{14-15}$. Therefore, in oxidative stress assays, tavarua deoxyriboside A was used at concentrations ranging from 1 to 1000 $\mathrm{nM}$, whilst jasplakinolide was tested at $0.01,0.1$ and $1 \mathrm{nM}$.

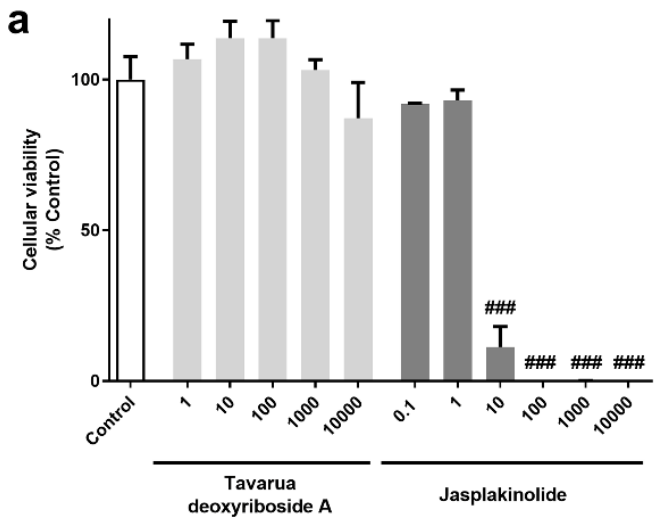

Concentration (nM)

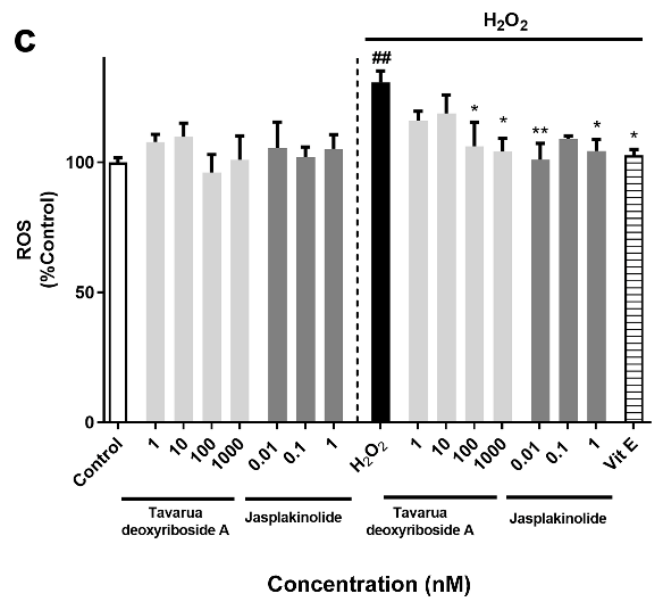

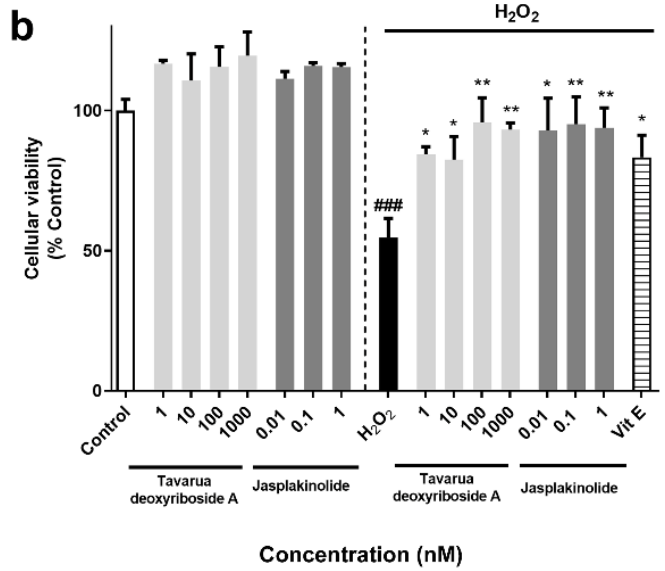

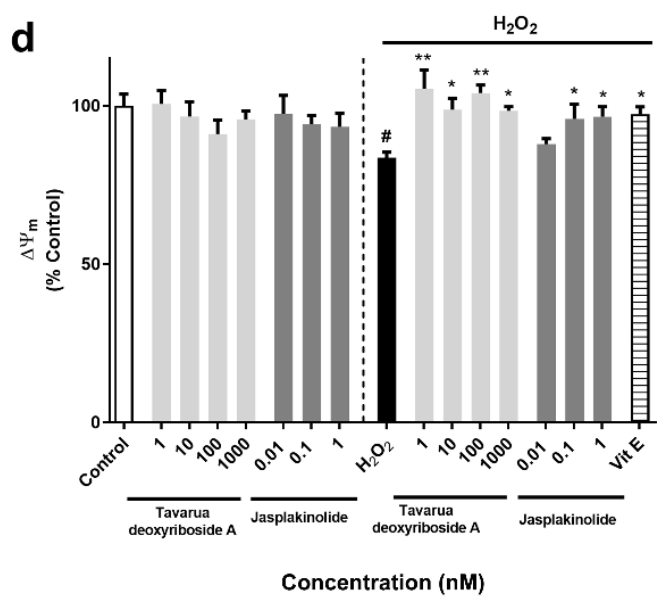

Figure 2. Cytotoxic and antioxidant effects of compounds on SH-SY5Y cells. (a) Cytotoxicity of tavarua A and jasplakinolide after $24 \mathrm{~h}$ incubation. (b) Cell viability of neuroblastoma cells after treatment with compounds for $6 \mathrm{~h}$ with and without $150 \mu \mathrm{M}$ $\mathrm{H}_{2} \mathrm{O}_{2}$. (c) Measurement of ROS levels after an incubation of $6 \mathrm{~h}$ with Fijian metabolites with and without $150 \mu \mathrm{M} \mathrm{H}_{2} \mathrm{O}_{2}$. (d) Effects of compounds on mitochondrial membrane potential $(\Delta \Psi \mathrm{m})$ after $6 \mathrm{~h}$ of incubation with or without $\mathrm{H}_{2} \mathrm{O}_{2}$. Vitamin $\mathrm{E}$ (Vit $\mathrm{E}$ ) at 25 $\mu \mathrm{M}$ was used as positive control in oxidative stress assays. Mean \pm SEM of three experiments performed by triplicate. Data expressed as percentage of control cells and compared by one-way ANOVA and Dunnett's tests. \# $p<0.05$, \#\# $p<0.01$, \#\#\# $p<0.001$ 
compared to untreated control cells. ${ }^{*} p<0.05$, ${ }^{*} p<0.01$ compared to cells treated with $\mathrm{H}_{2} \mathrm{O}_{2}$ alone

To determine the neuroprotective effects of compounds against oxidative stress, $\mathrm{SH}$ SY5Y cells were co-treated with the secondary metabolites and $150 \mu \mathrm{M} \mathrm{H}_{2} \mathrm{O}_{2}$ for $6 \mathrm{~h}^{16}$. Firstly, the capacity of compounds to improve cell survival was analysed with MTT test (Figure 2b). Treatment with compounds alone does not produce any toxicity on neuroblastoma cells. The addition of $150 \mu \mathrm{M} \mathrm{H}_{2} \mathrm{O}_{2}$ significantly reduced cell survival $(54.7 \pm 6.8 \%, p<0.001)$. This decrease was recovered by both compounds at all the concentrations assayed. Tavarua deoxyriboside A increased cell survival until levels among 82.5-95.8\% of control cells, and treatment with jasplakinolide reached percentages of $92.9-95.2 \%$. These results were similar to those obtained with the known antioxidant Vitamin $\mathrm{E}$ (Vit E) at $25 \mu \mathrm{M}(87.5 \pm 7.6 \%, p<0.05)$.

Next, the effect of compounds on ROS release was evaluated. As Figure 2c shows, neither tavarua A nor jasplakinolide affected ROS levels when added alone. Otherwise, compounds reduced ROS levels when SH-SY5Y cells were treated with the pro-oxidant. Cells treated only with $150 \mu \mathrm{M} \mathrm{H}_{2} \mathrm{O}_{2}$ presented a significant increase in ROS levels $(127.7 \pm 4.3 \%, p<0.01)$ compared to untreated cells. Addition of tavarua A at 100 and 1000 $\mathrm{nM}$ decreased ROS release to $106.2 \pm 9.3 \% \quad(p<0.05)$ and $104.2 \pm 5.1 \% \quad(p<0.05)$, respectively. ROS levels were also reduced by jasplakinolide at $0.01 \mathrm{nM}(101 \pm 6.3 \%$, $p<0.01)$ and $1 \mathrm{nM}(104.4 \pm 4.4 \%, p<0.05)$.

We finally determined whether compounds were able to improve mitochondrial function, since the organelle is the main producer of ROS and its dysfunction is closely related to neurodegeneration ${ }^{17}$. Therefore, $\Delta \Psi_{\mathrm{m}}$ was analysed with the fluorescent dye tetramethyl rhodamine methyl ester (TMRM) after treatment with tavarua A and jasplakinolide for 6 h, with and without presence of $\mathrm{H}_{2} \mathrm{O}_{2}$ (Figure 2d). The addition of compounds alone did 
not affect to $\Delta \Psi \mathrm{m}$, whereas treatment with the pro-oxidant depolarized the mitochondrial membrane up to $83.5 \pm 1.8 \%(p<0.05)$. Tavarua A significantly recovered $\Delta \Psi_{\mathrm{m}}$, increasing TMRM signal at all the concentrations assayed until levels among 96.1-105.3\%. Treatment with jasplakinolide also improved mitochondrial function at the highest concentrations $(0.1$ and $1 \mathrm{nM})$, with levels of $98.0 \pm 5.7 \%(p<0.05)$ and $96.5 \pm 3.2 \%$ $(p<0.05)$, respectively.

In view of the promising results obtained, we next examined the effects of compounds on the antioxidant defences of neuronal cells. At first, the amount of GSH, the main nonenzymatic antioxidant in cells, was evaluated (Figure 3a). Addition of $1000 \mathrm{nM}$ tavarua deoxyriboside A alone produced a significant increase in GSH levels until 146.2 $\pm 14.7 \%$ $(p<0.05)$, and treatment with jasplakinolide at $1 \mathrm{nM}$ also augmented $\mathrm{GSH}$ content to $125.3 \pm 3.7 \%(p<0.05)$ of untreated cells. In the oxidative stress model, SH-SY5Y cells treated with $150 \mu \mathrm{M} \mathrm{H}_{2} \mathrm{O}_{2}$ presented a reduction in $\mathrm{GSH}$ content $(74.3 \pm 6.0 \%, p<0.01)$, which was recovered by both marine compounds. Tavarua deoxyriboside A significantly increased the antioxidant molecule at $10(114.4 \pm 11.9 \%, p<0.01), 100(118.3 \pm 4.4 \%$, $p<0.01)$ and $1000 \mathrm{nM}(123.4 \pm 2.8 \%, p<0.01)$. Treatment with jasplakinolide also augmented GSH levels to percentages among 92.5-102.5\% of control cells. The recovery of GSH content with compounds was similar to the result obtained with $25 \mu \mathrm{M}$ Vit E $(109.7 \pm 4.0 \%, p<0.01)$.

Then, the activity of superoxide dismutases (SODs) was evaluated. This enzymatic family is one of the main antioxidant systems in cells, specialized in eliminating superoxide ions. In this case, treatment with compounds alone did not produce any effect on SODs activity (Figure $3 b$ ). Addition of $150 \mu \mathrm{M} \mathrm{H}_{2} \mathrm{O}_{2}$ reduced the enzyme activity $(77.2 \pm 1.9 \%, p<0.05$ ), a decrease that was recovered by tavarua deoxyriboside A. The compound increased 
SODs activity at concentrations ranging from 1-100 $\mathrm{nM}$ to levels about $94 \%(p<0.05)$ of control cells.
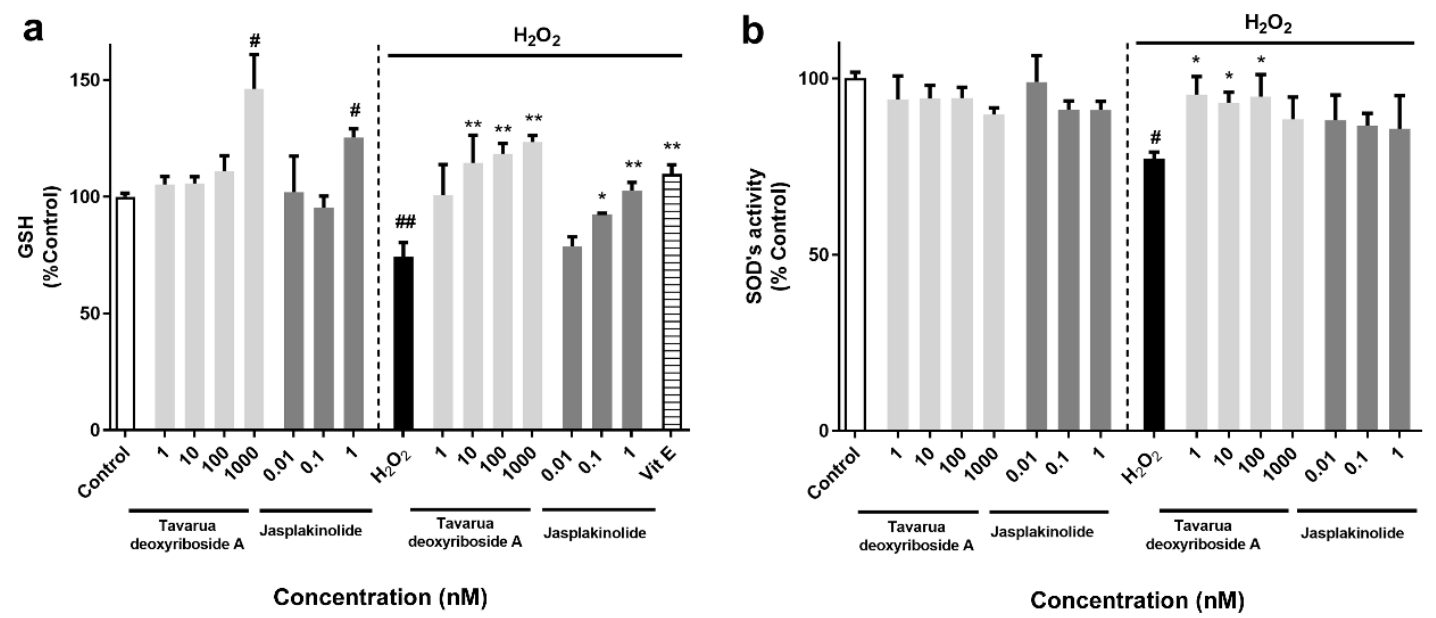

Figure 3. Evaluation of compound effects on antioxidant systems in neuroblastoma cells. Cells were treated with tavarua deoxyriboside $\mathrm{A}$ and jasplakinolide at non-toxic concentrations with or without $150 \mu \mathrm{M} \mathrm{H}_{2} \mathrm{O}_{2}$ for $6 \mathrm{~h}$. (a) $\mathrm{GSH}$ levels. (b) Activity of SODs. Mean \pm SEM of three replicates presented as percentage of control cells. Vitamin $\mathrm{E}$ (Vit E) at $25 \mu \mathrm{M}$ was used as positive control. Statistical differences were determined by one-way ANOVA test followed by Dunnett's post hoc test. \# $p<0.05$, \#\# $p<0.01$ compared to untreated control cells. * $p<0.05$, ** $p<0.01$ compared $\mathrm{H}_{2} \mathrm{O}_{2}$ control cells

The results obtained in oxidative stress assays, in which Fijian compounds were able to protect $\mathrm{SH}-\mathrm{SY} 5 \mathrm{Y}$ cells from $\mathrm{H}_{2} \mathrm{O}_{2}$ damage by reducing $\mathrm{ROS}$ and improving antioxidant systems, led us to analyse the effect of compounds on Nuclear factor E2-related factor (Nrf2). The translocation of this transcription factor to the nucleus induces the expression of several antioxidant enzymes, as well as genes related to mitochondrial function ${ }^{18}$. In this context, neuroblastoma cells were treated with compounds for $6 \mathrm{~h}$ and Nrf2 
expression was determined by Western blot in the nuclear and cytosolic fractions (Figure 4).
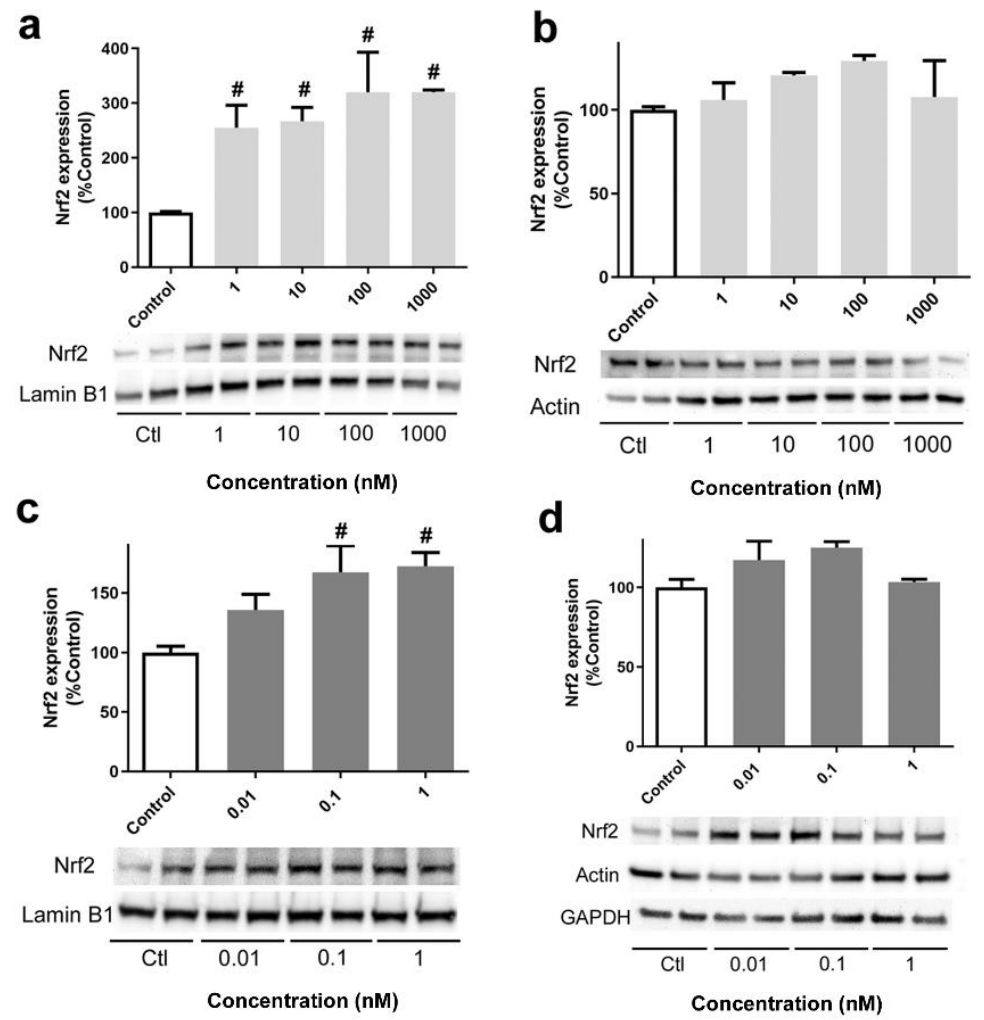

Figure 4. Nrf2 expression in SH-SY5Y cells after treatment with Fijian metabolites. Cells were treated with compounds for $6 \mathrm{~h}$ and the expression of the transcription factor was determined by western blot. (a) Nrf2 expression in the nuclear fraction of cells treated with tavarua deoxyriboside A. (b) Cytosolic expression in SH-SY5Y cells after addition of tavarua deoxyriboside A. (c) Nuclear expression of Nrf2 in neuroblastoma cells treated with jasplakinolide. (d) Expression of the transcription factor in the cytosol after treatment with jasplakinolide. Protein band expression was normalized by lamin B1 and actin in nuclear and cytosolic fractions, respectively. In the case of jasplakinolide, cytosolic band expression was also normalized with GAPDH. Results are mean \pm SEM of three replicates carried out by duplicate, expressed as percentage of control cells. 
Statistical significance determined by one-way ANOVA and Dunnett's tests. \# $p<0.05$ compared to control cells

Treatment with tavarua deoxyriboside A produced a significant increase in Nrf2 nuclear expression, reaching levels between 320.2-243.8\% of control cells (Figure 4a). With respect to cytosolic expression, no significant differences were found (Figure 4b). Jasplakinolide also augmented the expression of Nrf2 in the nucleus when neuroblastoma cells were treated with the compound at $0.1(125.1 \pm 3.8 \%, p<0.05)$ and $1 \mathrm{nM}$ $(117.3 \pm 11.9 \%, p<0.05)$ (Figure 4c). Again, the expression of the transcription factor in the cytosol did not present differences after treatment with the compound (Figure 4d). Due to the known effects of jasplakinolide on actin polymerization at toxic concentrations, the cytosolic expression of Nrf2 was normalized using both anti-actin and anti- glyceraldehyde-3-phosphate dehydrogenase (GAPDH) antibodies. No differences in Nrf2 expression were found after normalizing its quantification with both proteins (data not shown), discarding an effect of the compound on actin at the concentrations used in these assays. Therefore, anti-actin antibody was used in the following experiments.

\subsection{Tavarua deoxyriboside A and jasplakinolide modulate the activation of microglia}

The effect of compounds on neuroinflammation was determined in BV2 murine microglial cells, which were pre-treated with compounds for $1 \mathrm{~h}$ and activated with 500 ng/mL lipopolysaccharide (LPS), a component of Gram-negative bacteria membrane, during $24 \mathrm{~h}^{19}$. Firstly, compound safety was evaluated with MTT assay. Cells were treated for $24 \mathrm{~h}$ at the concentrations used in oxidative stress assays, and no cytotoxicity was observed (data not shown).

Then, the levels of ROS production were determined after treatment with compounds in non-activated and LPS-activated cells (Figure 5a). The addition of tavarua A and 
jasplakinolide alone did not affect to ROS release at any of the concentrations tested. Microglial activation with the endotoxin augmented ROS production up to $155.6 \pm 10.8 \%$ $(p<0.01)$, an increase significantly reduced by pre-treatment with both secondary metabolites. Tavarua deoxyriboside A diminished ROS levels at the four concentrations assayed, reaching the highest inhibition at $1000 \mathrm{nM}(79.4 \pm 1.6 \%, p<0.001)$. Jasplakinolide reduced ROS release at $0.01(113.5 \pm 3.2 \%, p<0.01)$ and $0.1 \mathrm{nM}(112.0 \pm 2.2 \%, p<0.01)$. We next evaluated the levels of GSH (Figure 5b), which did not present differences after treatment with compounds alone compared to inactivated cells. However, the activation with LPS produced a decrease in GSH content $(80.2 \pm 2.0 \%, p<0.01)$. Both compounds increased the levels of the antioxidant molecule, tavarua $\mathrm{A}$ at $1(95.6 \pm 2.6 \%, p<0.05)$ and $100 \mathrm{nM}(93.9 \pm 4.1 \%, p<0.05)$, and jasplakinolide at the lowest concentration $(90.9 \pm 4.1 \%$, $p<0.05)$.

a

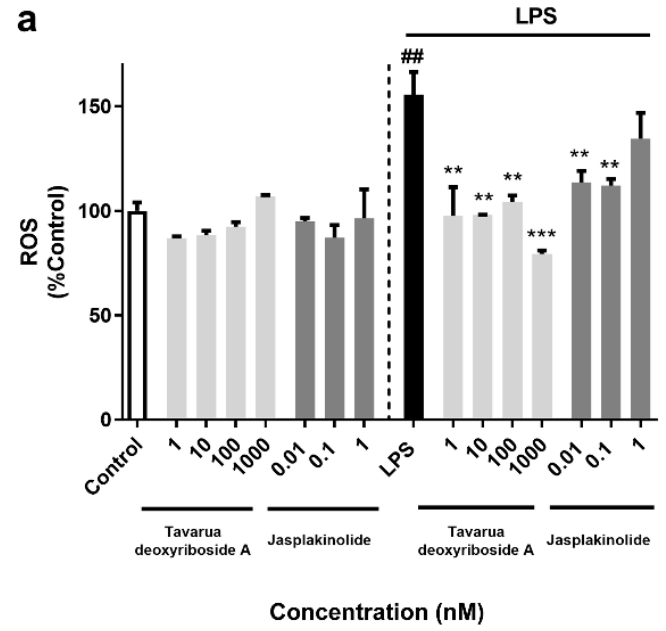

b

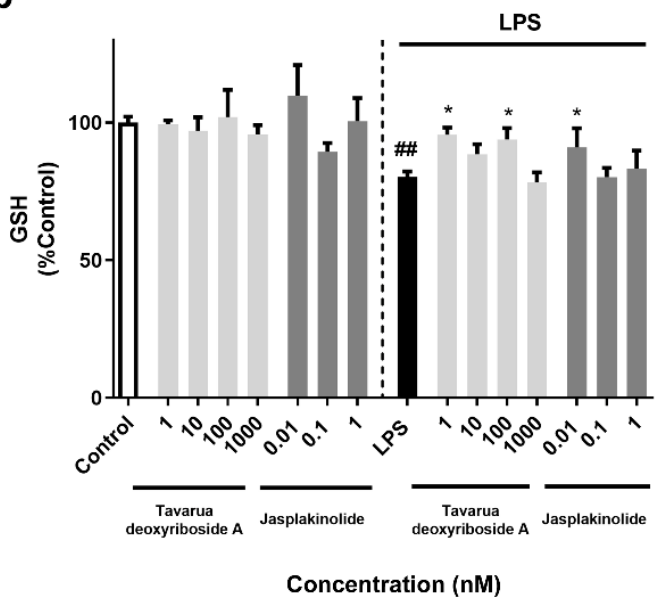

Figure 5. Effect of compounds on oxidative stress mediators in BV2 microglial cells. Cells were pre-treated with metabolites for $1 \mathrm{~h}$, followed by addition of $500 \mathrm{ng} / \mathrm{mL}$ LPS during $24 \mathrm{~h}$. Microglia was also treated with compounds alone to determine their effects on cells activation. (a) Measurement of ROS levels. (b) Determination of GSH content. Values presented as percentage of control cells. Mean \pm SEM of three replicates 
performed by triplicate, compared by one-way ANOVA and Dunnett's tests. \#\# $p<0.01$ compared to inactivated cells. ${ }^{*} p<0.05,{ }^{* *} p<0.01$, $* * * p<0.001$ compared to LPS control cells

In view of the reduction in ROS release generated by the compounds, their effects on NADPH-oxidase (NOX) expression were evaluated. The enzyme is the principal source of ROS production in microglial cells, and is composed by five subunits: p40phox, p47phox, p67phox, p22phox and gp91phox. The latter, located in the plasma membrane, is the main responsible for superoxide production ${ }^{20}$, so its expression was quantified in the membrane and the cytosol of BV2 cells (Figure 6).
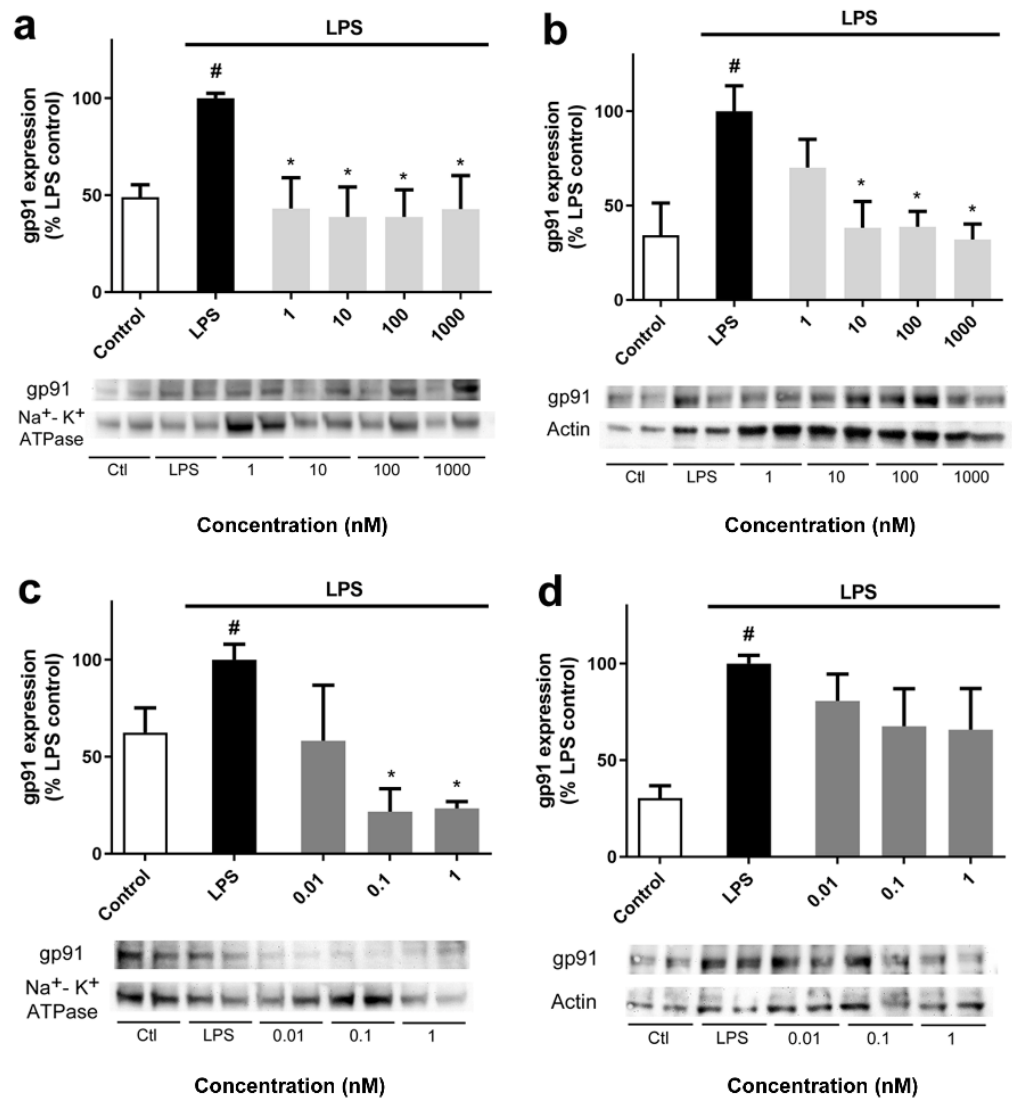

Figure 6. Evaluation of gp91 expression in microglia. BV2 cells were treated during $1 \mathrm{~h}$ with compounds, followed by stimulation with $500 \mathrm{ng} / \mathrm{mL}$ LPS for $24 \mathrm{~h}$. gp91 expression in the (a) membranous fraction and (b) cytosolic fraction of cells treated with tavarua 
deoxyriboside A. (c) Expression of the NOX subunit in the membrane after treatment with jasplakinolide. (d) Cytosolic expression of gp91 in BV2 cells treated with jasplakinolide. Protein band expression was normalized by $\mathrm{Na}^{+}-\mathrm{K}^{+}$ATPase and actin in membranous and cytosolic fractions, respectively. Mean \pm SEM of four replicates performed by triplicate, compared by one-way ANOVA and Dunnett's tests. \# $p<0.05$ compared to inactivated control cells. ${ }^{*} p<0.05$ compared to LPS control cells

Due to the lack of effect of the treatment with compounds alone on microglial activation, these experiments were performed only in LPS-activated cells. Pre-treatment with tavarua deoxyriboside A produced a significant decrease in gp91 expression in both fractions (Figure 6a-b), reaching levels of inactivated cells. In the case of jasplakinolide, a reduction in gp91 expression was observed in the membranous fraction (Figure 6c) at 0.1 and $1 \mathrm{nM}$, with percentages ranging between $21.7 \pm 11.7 \%$ and $23.3 \pm 3.5 \%(p<0.05)$ of LPS-activated cells. On the other hand, this compound did not present any effects on the cytosolic expression of NOX subunit (Figure 6d).

The study of neuroinflammation was followed by assessing the release of the proinflammatory mediators NO, IL-6 and TNF- $\alpha$, and the anti-inflammatory molecule interleukin-10 (IL-10) (Figure 7). Regarding NO, as Figure 7a shows, LPS addition significantly augmented its release a $47.9 \pm 6.3 \%(p<0.001)$ with respect to inactivated cells. Tavarua deoxyriboside A diminished NO levels to percentages about 74.7-83.6\% of LPS control cells. Jasplakinolide also decreased its release at the highest concentrations assayed $(0.1$ and $1 \mathrm{nM})$ with levels of $72.9 \pm 1.7 \%(p<0.05)$ and $76.6 \pm 0.5 \%(p<0.05)$, respectively. Next, the expression of inducible nitric oxide synthase (iNOS), the enzyme responsible for NO production, was assessed. The enzyme was not detected in inactivated cells, but stimulation of microglial cells with LPS induced a significant augmentation of its expression. Addition of tavarua deoxyriboside A produced a reduction in iNOS 
expression at 1 and $10 \mathrm{nM}(54.5 \pm 5.3 \%$ and 55.2 $\pm 9.0 \%$, respectively) (Figure $7 \mathrm{~b})$, whereas no differences were found after treatment with jasplakinolide (Figure 7c).

a
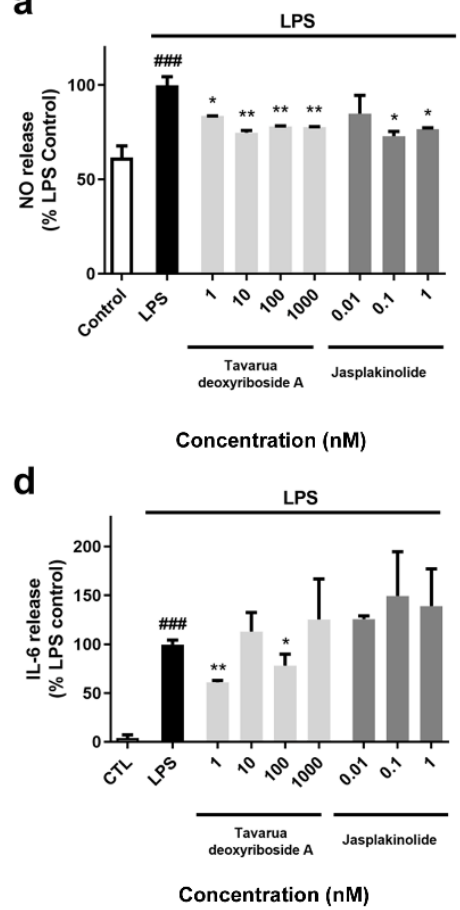

b

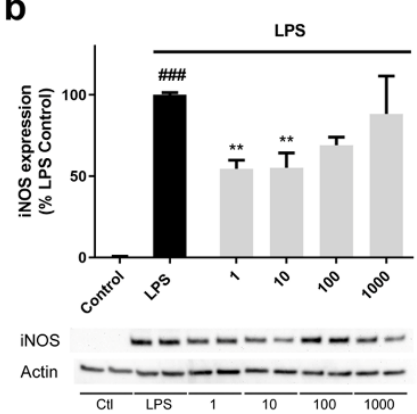

Concentration (nM)

$\mathbf{e}$

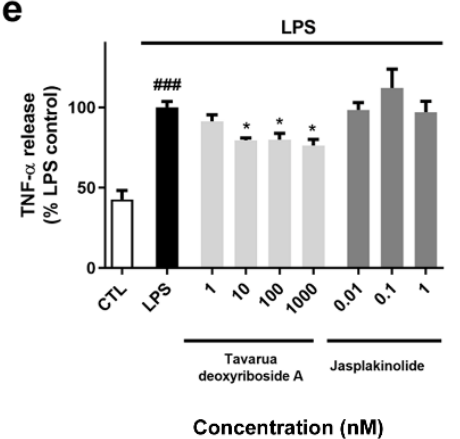

C
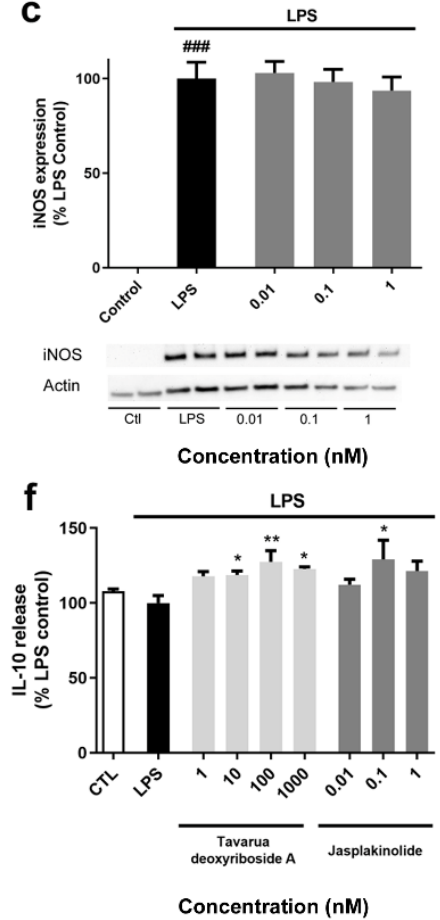

Figure 7. Analysis of neuroinflammation mediators after treatment with Fijian metabolites. BV2 microglial cells were pre-treated with compounds at non-toxic concentrations for $1 \mathrm{~h}$ and $500 \mathrm{ng} / \mathrm{mL}$ LPS for $24 \mathrm{~h}$. (a) NO levels in microglial medium, and (b) iNOS expression after treatment with tavarua deoxyriboside $\mathrm{A}$ and (c) jasplakinolide. (d) IL-6 release, (e) TNF- $\alpha$ content and (f) IL-10 levels in BV2 medium. Values expressed as percentage of cells treated with LPS alone. Mean \pm SEM of three replicates. Statistical differences determined by one-way ANOVA followed by Dunnett's post hoc test. \#\#\# $p<0.001$ compared to inactivated cells. ${ }^{*} p<0.05$, ${ }^{* *} p<0.01$ compared LPS control cells

Next, the amount of IL-6 in cell medium was monitored (Figure 7d). The differences among inactivated and LPS-activated cells reached a 99.9\% $(p<0.001)$. Only tavarua A reduced the cytokine release at $1 \mathrm{nM}(60.9 \pm 1.8 \%, p<0.05)$ and $100 \mathrm{nM}(77.9 \pm 11.9 \%$, 
$p<0.05)$. The same occurred with TNF- $\alpha$, which was significantly decreased by tavarua $\mathrm{A}$ at the highest concentrations with levels ranging between $76.3-89.8 \% \quad(p<0.05)$ compared to LPS control cells (Figure 7e). Finally, the anti-inflammatory cytokine IL-10 was quantified in BV2 medium (Figure 7f). Tavarua A increased its release at the highest concentrations, being $100 \mathrm{nM}$ the most effective $(127.4 \pm 7.4 \%, p<0.01)$. Jasplakinolide also augmented IL-10 levels when added to BV2 cells at $0.1 \mathrm{nM}$, with a percentage of $129.1 \pm 12.9 \%(p<0.05)$.

The transcription factor Nuclear factor kappa-light-chain-enhancer of activated B cells $(\mathrm{NFkB})$ is considered the most important regulator of the inflammatory cascade, so we next determined its expression. In particular, the levels of the domain p65 were assessed, since its increase in the nucleus leads to the expression of pro-inflammatory mediators ${ }^{21}$. The results obtained are shown in Figure 8.

a
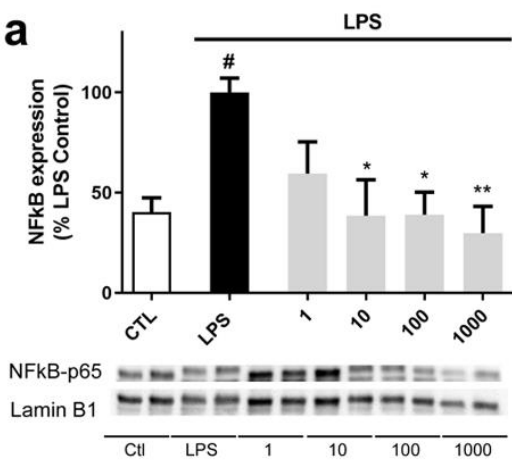

C
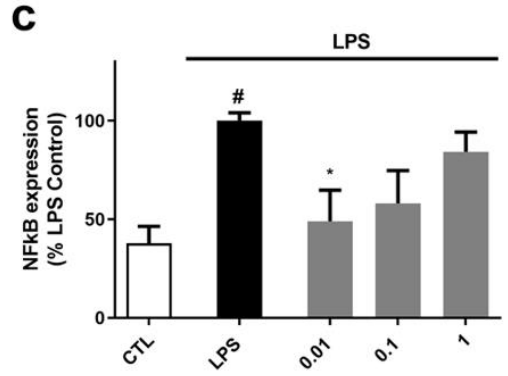

NFkB-p65 - - - - - - -

Lamin B1 $\frac{-}{\mathrm{CH}} \frac{-}{\mathrm{LPS}} \frac{-}{0.01} \frac{-1}{0.1}$

Concentration (nM) b
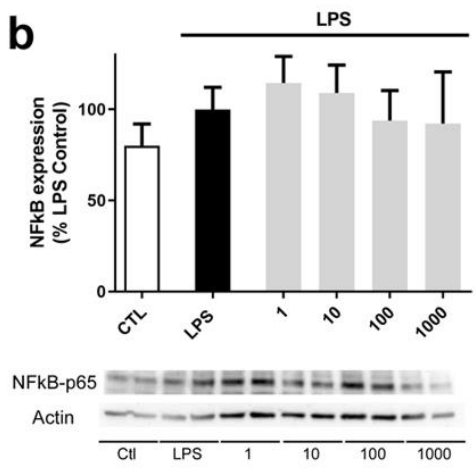

d
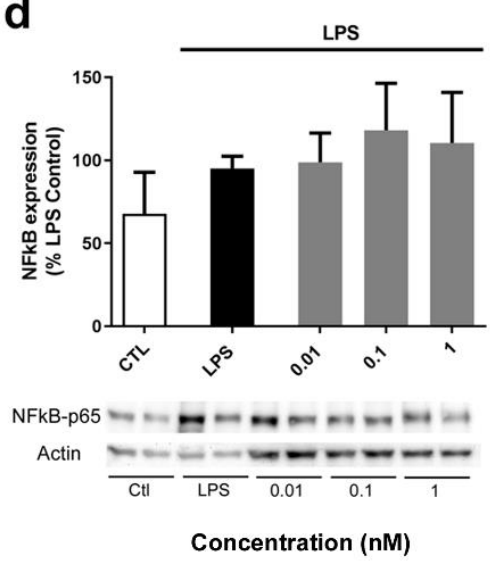
Figure 8. Effect of Fijian compounds on NFkB expression in microglial cells. BV2 cells were pre-treated with compounds for $1 \mathrm{~h}$ and activated with $500 \mathrm{ng} / \mathrm{mL}$ LPS during $24 \mathrm{~h}$. (a) Nuclear and (b) cytosolic expression of NFkB-p65 after addition of tavarua deoxyriboside A. (c) Expression of the transcription factor in the nuclear and (d) cytosolic fractions after treatment with jasplakinolide. Protein band expression was normalized by lamin B1 and actin in nuclear and cytosolic fractions, respectively. Mean \pm SEM of four replicates performed by duplicate, compared by one-way ANOVA and Dunnett's tests. $\# p<0.01$ compared to inactivated cells. ${ }^{*} p<0.05,{ }^{* *} p<0.01$ compared to cells treated with LPS alone.

As expected, NFkB -p65 expression was increased about 50\% in LPS-activated cells. Tavarua A reduced the transcription factor expression at the highest concentrations, with levels around 29.8-39\% of LPS control cells (Figure 8a). Otherwise, the cytosolic expression remained unaffected (Figure 8b). Treatment with $0.01 \mathrm{nM}$ jasplakinolide also reduced the nuclear expression of p65 $(48.9 \pm 15.8 \%, p<0.05)$ (Figure $8 \mathrm{c})$, whilst no effect was found on cytosolic levels (Figure 8d).

Due to the results obtained in SH-SY5Y cells and its involvement in antioxidant and antiinflammatory responses ${ }^{22}$, we next analysed Nrf2 expression. As Figure 9 shows, only tavarua deoxyriboside A induced a significant increase in Nrf2 nuclear expression, reaching a percentage of $134.8 \pm 19.5 \%(p<0.05)$ at $100 \mathrm{nM}$ (Figure 9a). 

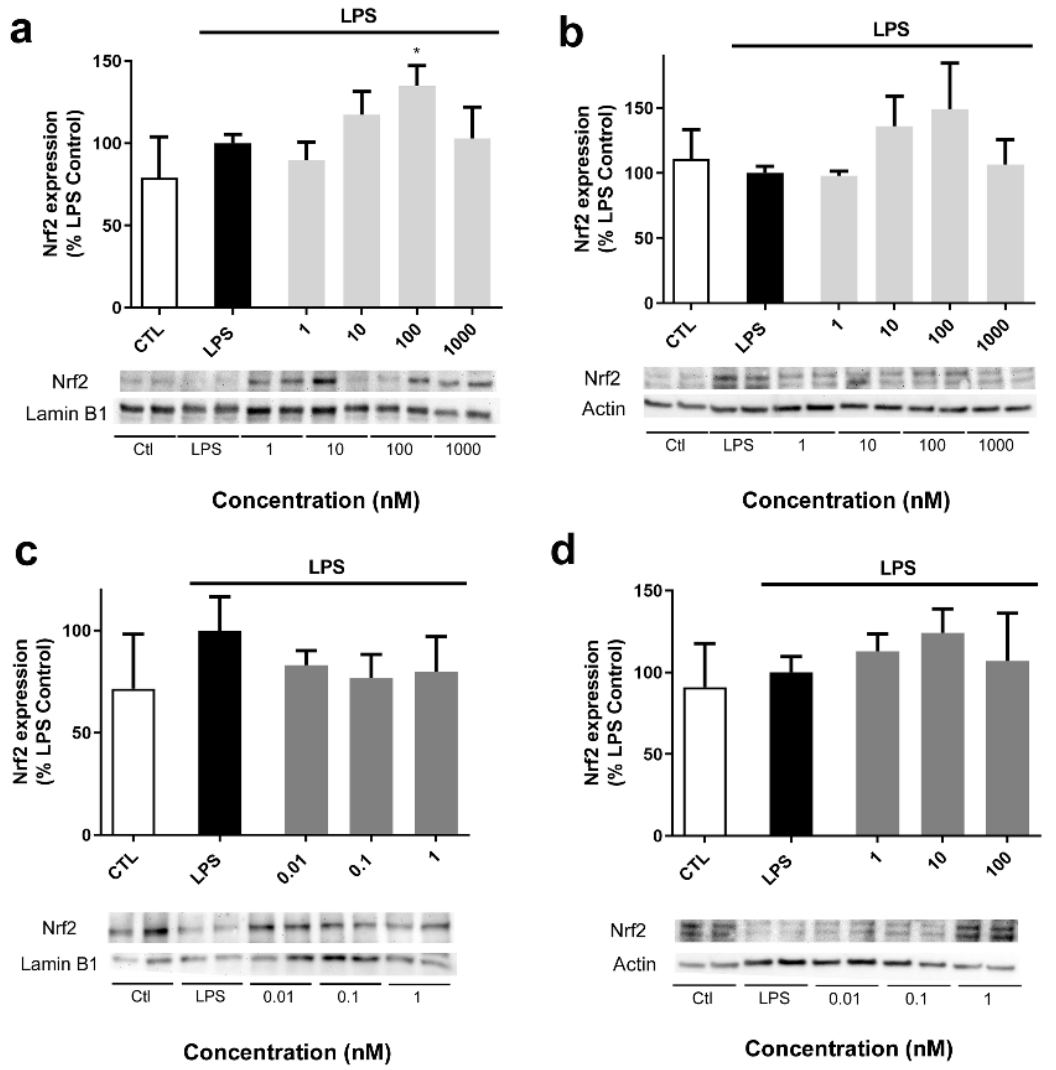

Figure 9. Nrf2 expression in microglial cells treated with Fijian metabolites. Compounds were added to BV2 for $1 \mathrm{~h}$, followed by treatment with $500 \mathrm{ng} / \mathrm{mL}$ LPS during $24 \mathrm{~h}$. Expression of the transcription factor in the (a) nucleus and (b) cytosol of microglia after treatment with tavarua deoxyriboside A. Nrf2 expression in (c) nuclear and (d) cytosolic fractions after addition of jasplakinolide. Protein band expression was normalized by lamin B1 and actin in nuclear and cytosolic fractions, respectively. Mean \pm SEM of four replicates performed by duplicate, compared by one-way ANOVA and Dunnett's tests. $* p<0.05$ compared to LPS control cells.

Finally, a trans-well co-culture between microglial and neuronal cells was carried out to confirm the neuroprotective properties of Fijian metabolites. BV2 cells were seeded in culture inserts placed on SH-SY5Y cells, and microglia was treated with compounds and LPS as described before. Then, neuroblastoma survival was determined with MTT test. 
As Figure 10 shows, the addition of $500 \mathrm{ng} / \mathrm{mL}$ LPS produced a decrease in SH-SY5Y cells viability $(85.8 \pm 0.5 \%, p<0.05)$. Treatment with tavarua deoxyriboside A protected neuroblastoma survival at 1,100 and $1000 \mathrm{nM}$ reaching percentages between 99.3$101.1 \%$ of cells co-cultured with inactivated microglia. Jasplakinolide also augmented the viability of neuroblastoma cells to $96.5 \pm 2.7 \%(p<0.05)$ at $0.01 \mathrm{nM}$.

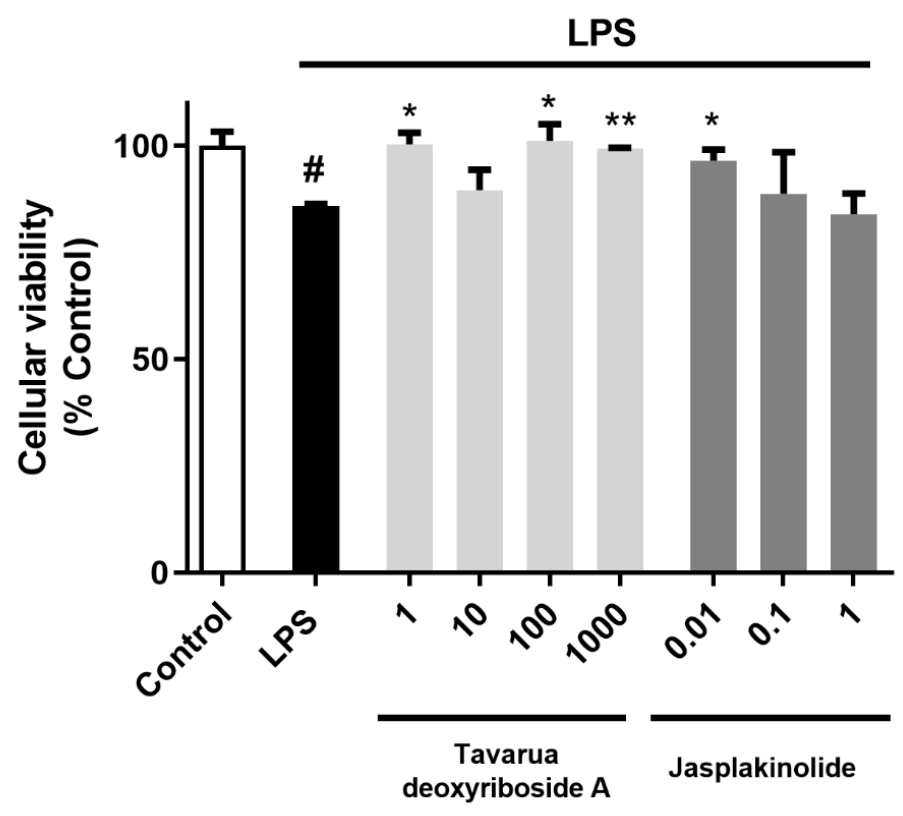

Figure10. Cell viability of SH-SY5Y cells in a trans-well co-culture with BV2 microglial cells. Microglia was seeded in inserts placed above neuroblastoma cells, treated with tavarua A deoxyriboside and jasplakinolide for $1 \mathrm{~h}$ and activated with $500 \mathrm{ng} / \mathrm{mL}$ LPS for $24 \mathrm{~h}$. Then, SH-SY5Y viability was determined by MTT test. Mean \pm SEM of three replicates performed by duplicate. Values expressed as percentage of cells co-cultured with inactivated microglia. Statistical differences determined by one-way ANOVA and Dunnett's tests. $\# p<0.05$ compared to control cells. ${ }^{*} p<0.05$, ${ }^{* *} p<0.01$ compared to cells co-cultured with microglia treated only with LPS 


\section{Discussion}

The search of compounds for the treatment of the most common neurodegenerative diseases, $\mathrm{AD}$ and $\mathrm{PD}$, has been traditionally focused on the disaggregation of protein deposits. In AD, much effort has been carried out with respect to amyloid beta aggregates, with several strategies, such as active and passive immunization or inhibition of key enzymes involved in the processing of this protein ${ }^{23}$. In the same way, PD research has been centred in $\alpha$-synuclein, mainly through the reduction of its synthesis, immunotherapy or anti-aggregative molecules ${ }^{24}$. However, due to the disappointing results obtained with these therapeutic approaches, other targets have emerged as promising pharmacological options, such as oxidative stress, mitochondrial dysfunction and neuroinflammation ${ }^{25-26}$. These pathological events occur on early phases of neurodegenerative diseases, so their simultaneous modulation could lead to slow the progress of the illnesses. Specifically, natural products present great potential as antioxidant and anti-inflammatory drugs and could be used for the treatment of neurodegeneration $^{27}$. In this context, the effects of tavarua deoxyriboside $\mathrm{A}$ and jasplakinolide were tested on in vitro models of oxidative stress and neuroinflammation for first time.

In neuronal cells, we observed that both Fijian compounds reduced ROS levels, improved mitochondrial function and enhanced the antioxidant defences. These neuroprotective properties seem to be mediated by the capacity of the metabolites to translocate Nrf2 to the nucleus. The transcription factor is an essential regulator of the expression of antioxidant enzymes (catalase, SODs, glutathione reductase ...) and its activity in neuronal cells is limited ${ }^{3}$, so its activation is crucial for counteracting neurodegeneration. In recent years, the classical role of $\mathrm{Nrf} 2$ as an inductor of antioxidant enzymes has been 
extended, and its function on mitochondrial metabolism, autophagy and inflammation has been revealed, making Nrf2 inductors promising drugs for facing neurodegeneration ${ }^{18}$. With regard to neuroinflammation, both compounds were able to reduce ROS levels and to improve GSH content in LPS-activated microglial cells. We therefore analysed their effects on NOX, the most important source of oxidants in microglial cells. In particular, the expression of the catalytic subunit of the enzyme, gp91, was determined. This subunit removes electrons from NADPH and transports them across the membrane to generate superoxide ${ }^{20}$. Our results indicate that both compounds diminish gp91 expression in the plasmatic membrane, so the decrease observed in ROS release may be related to this inhibition. NADPH plays a pivotal role in microglial activation, since it is also needed for GSH generation by glutathione reductase and for iNOS activity ${ }^{28}$. A reduction in NO levels was also produced by compounds, so the decrease in NADPH consumption by NOX and iNOS could be involved in the increase in GSH content produced by compounds.

All these effects are also related to the inhibition of NFkB activation by both compounds. The enzyme is a crucial regulator of the inflammatory response, when it is translocated to the nucleus, the transcription factor interacts with the promoter region of the iNOS gene, inducing its expression ${ }^{29}$. Otherwise, the interplay among NFkB and NOX is unclear, since gp91 overexpression increases NFkB activation and viceversa. The transcription factor activation is also responsible of IL-6 and TNF- $\alpha$ release ${ }^{30}$, so the reduction in their levels produced by tavarua deoxyriboside $\mathrm{A}$ is due to its ability to inhibit NFkB translocation.

Tavarua deoxyriboside A was also capable of activating Nrf2 in BV2 cells. The transcription factor, together to its antioxidant properties, is involved in microglial activation. Nrf2 represses the activation of pro-inflammatory genes and potentiates the 
anti-inflammatory signalling, i.e. it inhibits the transcription of IL- 6 and IL- $1 \beta$ by binding to DNA sequences near to their genes ${ }^{31}$.Therefore, to some extent, Nrf2 acts as an antagonist of NFkB. The activation of both transcription factors is tightly regulated by the redox status of the cells ${ }^{6}$ and there are many evidences of an interplay between these pathways at molecular level ${ }^{32}$.

The upregulation of IL-10 by Fijian metabolites is also remarkable, because the cytokine is involved in the inhibition of many pro-inflammatory genes (IL-1, TNF- $\alpha$, IL-6...), reduces NFkB translocation ${ }^{33}$ and inhibits NOX activity ${ }^{20}$. In summary, both jasplakinolide and tavarua deoxyriboside A affected key pathways involved in neuroinflammation, but the latter presented more promising results in the modulation of microglial immune response. In fact, the co-culture between microglial and neuronal cells further confirmed the neuroprotective effects of this compound. In this assay, jasplakinolide also presented positive results at picomolar concentrations, probably related to its effects on ROS and NO.

It should be noted that jasplakinolide has presented anticancer properties in several cell lines through the induction of actin polymerization ${ }^{15}$. These anticancer effects were found at concentrations among 50-100 nM, whilst the neuroprotective characteristics of jasplakinolide reported in this work have been obtained at picomolar concentrations. This dual behaviour has been reported in natural compounds such as curcumin, resveratrol or quercetin, which present antioxidant and anti-inflammatory effects at low doses, and anticancer and pro-inflammatory properties at higher concentrations ${ }^{34-36}$.

In conclusion, we have demonstrated for first time the neuroprotective capacity of tavarua deoxyriboside A and jasplakinolide, related to their ability to activate Nrf2 and to affect to crucial enzymes involved in inflammation, such as NFkB and gp91. The results 
obtained make these marine compounds promising molecules for future studies about their effects on neurodegenerative diseases.

\section{Material and methods}

\subsection{Chemicals and solutions}

TMRM, Thiol Tracker ${ }^{\mathrm{TM}}$ Violet, 5-(and-6)-carboxy-2', 7'-dichlorodihydrofluorescein diacetate (carboxy- $\mathrm{H}_{2}$ DCFDA), Griess Reagent Kit, Pierce ${ }^{\mathrm{TM}}$ Protease Inhibitor Mini Tablets, Pierce TM Phosphatase Inhibitor Mini Tablets, Supersignal West Pico Luminiscent Substrate and Supersignal West Femto Maximum Sensitivity Substrate were purchased from Thermo Fisher Scientific (Waltham, MA, USA). Other chemical were reagent grade and purchased from Sigma-Aldrich (Madrid, Spain).

\subsection{Isolation of compounds}

Tavarua deoxyriboside A was obtained from the tunicate Tavarua-2, belonging to the family Didemnidae, collected in the island of Tavarua at a depth of $20 \mathrm{~m}$, as previously described ${ }^{11}$. Samples were extracted with $\mathrm{MeOH}$ and $\mathrm{CH}_{2} \mathrm{Cl}_{2}$, placed in glass vials, and dried under the flow of nitrogen gas at $39^{\circ} \mathrm{C}$ using a Microlab Aarhus A/S Supertherm mini-oven evaporator. The dried samples were then fractionated based on polarity using C18 SPE cartridges. Each sample was loaded to the SPE cartridge and then flushed with $100 \% \mathrm{H}_{2} \mathrm{O}$ to remove salts and highly polar compounds. This was followed by flushing with $25 \% \mathrm{MeOH}$ in $\mathrm{H}_{2} \mathrm{O}, 50 \% \mathrm{MeOH}-\mathrm{H}_{2} \mathrm{O}$, then by $100 \% \mathrm{MeOH}$. Finally, the column was flushed with $100 \% \mathrm{MeOH}$ containing $0.05 \%$ trifluoroacetic acid. The SPE-50 fraction of Tavarua- 2 was purified using an ACE 5 C18 HL, $250 \times 100 \mathrm{~mm}$ HPLC column and a solvent gradient system from 0 to $100 \% \mathrm{CH}_{3} \mathrm{CN}$ containing $0.05 \%$ trifluoroacetic acid in $30 \mathrm{~min}$ at a flow rate of $1.5 \mathrm{~mL} / \mathrm{min}$ to yield Tavarua deoxyriboside A (1.2 $\mathrm{mg})$. 
Jasplakinolide was isolated from the sponge Jaspis splendens, collected from Suva Harbour, Fiji Islands and extracted with $\mathrm{MeOH}$ and dichloromethane, dried and transported to Aberdeen. The sample was fractionated on Sephadex LH-20 using $\mathrm{CH} 2 \mathrm{Cl} 2-\mathrm{MeOH}(1: 1)$. The fraction containing jasplakinolide was purified by C18 HPLC using acetonitrile--water (80: 20) as solvent ${ }^{12}$.

\subsection{Cell culture}

Human neuroblastoma SH-SY5Y cell line was obtained from American Type Culture Collection (ATCC), number CRL2266. Cells were cultured in Dulbecco's Modified Eagle's medium: Nutrient Mix F-12 (DMEM/F-12) supplemented with $10 \%$ fetal bovine serum (FBS), $1 \%$ glutamax, $100 \mathrm{U} / \mathrm{mL}$ penicillin and $100 \mu \mathrm{g} / \mathrm{mL}$ streptomycin. BV2 murine microglial cell line was purchased from Interlab Cell Line Collection (ICLC), number ATL03001. Cells were maintained in RPMI 1640 medium with $10 \%$ FBS, 100 $\mathrm{U} / \mathrm{mL}$ penicillin and $100 \mu \mathrm{g} / \mathrm{mL}$ streptomycin. Cells were maintained at $37^{\circ} \mathrm{C}$ in a humidified atmosphere of 5\% CO2 and 95\% air. SH-SY5Y were dissociated weekly using $0.05 \%$ trypsin/EDTA, whilst BV2 cells were sub-cultured twice a week. All the reagents were provided by Thermo Fischer Scientific.

\subsection{Cell viability assessment}

The cytotoxicity of compounds was determined with MTT (3-(4, 5-dimethyl thiazol-2yl)-2, 5-diphenyl tetrazolium bromide) assay, as previously described ${ }^{16}$. Cells were treated with compounds $(0.1 \mathrm{nM}-10 \mu \mathrm{M})$ for $24 \mathrm{~h}$. After the incubation, cells were washed three times with Locke`s solution $(154 \mathrm{mM} \mathrm{NaCl}, 5.6 \mathrm{mM} \mathrm{KCl}, 1.3 \mathrm{mM} \mathrm{CaCl} 2,1 \mathrm{mM}$ $\mathrm{MgCl}_{2}, 5.6 \mathrm{mM}$ glucose and $10 \mathrm{mM}$ HEPES, $\mathrm{pH}$ 7.4). Then, $500 \mu \mathrm{g} / \mathrm{mL}$ MTT dissolved in Locke's buffer was added to the cells, which were incubated in an orbital shaker at 300 $\mathrm{rpm}$ and $37^{\circ} \mathrm{C}$ for $1 \mathrm{~h}$. Finally, cells were disaggregated with 5\% sodium dodecyl sulphate 
and the absorbance of formazan crystals was measured at $595 \mathrm{~nm}$ with a spectrophotometer plate reader. Saponin from quillaja bark at $40 \mathrm{mg} / \mathrm{mL}$ was used as death control and its absorbance was subtracted from the other data. The experiments were carried out three times.

\subsection{Mitochondrial membrane potential and neuroprotection assays}

For oxidative stress assays, SH-SY5Y cells were co-treated with the compounds at nontoxic concentrations and $150 \mu \mathrm{M} \mathrm{H}_{2} \mathrm{O}_{2}$ for $6 \mathrm{~h}$. Vit $\mathrm{E}$ at $25 \mu \mathrm{M}$ was used as positive control. All the experiments were performed as previously described ${ }^{16}$.

The ability of Fijian compounds to recover $\Delta \Psi_{\mathrm{m}}$ was determined with TMRM dye. Cells were rinsed twice with Locke's solution and TMRM at $1 \mu \mathrm{M}$ was added to each well. The plate was incubated in an orbital shaker at $300 \mathrm{rpm}$ and $37^{\circ} \mathrm{C}$ for $30 \mathrm{~min}$, and cells were lysed with $\mathrm{H}_{2} \mathrm{O}$ and DMSO mixture (1:1). The fluorescence was read in a spectrophotometer plate reader at $535 \mathrm{~nm}$ excitation and $590 \mathrm{~nm}$ emission.

The capacity of compounds to protect $\mathrm{SH}-\mathrm{SY} 5 \mathrm{Y}$ cells from $\mathrm{H}_{2} \mathrm{O}_{2}$ damage was determined with MTT assay as described above. All the assays were performed three independent times.

\subsection{Determination of superoxide dismutases activity}

SODs activity was determined with a SOD determination Kit (Sigma-Aldrich), following manufacturer's instructions. Briefly, SH-SY5Y cells were seeded in 12-well plates at $5 \times 10^{5}$ cells per well and incubated with compounds and $150 \mu \mathrm{M} \mathrm{H}_{2} \mathrm{O}_{2}$ for $6 \mathrm{~h}$. Then, 100 $\mu \mathrm{L}$ of lysis buffer $(0.1 \mathrm{M}$ Tris- $\mathrm{HCl}, \mathrm{pH} 7.4$ containing $0.5 \%$ Triton $\mathrm{X}-100,5 \mathrm{mM} \beta$ mercaptoethanol and $0.1 \mathrm{mg} / \mathrm{mL}$ PMSF) were added to each well. Lysates were centrifuged for $5 \mathrm{~min}$ at $14000 \mathrm{~g}$ and $4^{\circ} \mathrm{C}$. Then, $20 \mu \mathrm{L}$ of each sample were mixed with $200 \mu \mathrm{L}$ of WST solution ((2-(4-Iodophenyl) -3-(4-nitrophenyl)-5-(2, 4-disulfophenyl) - 
$2 \mathrm{H}$ tetrazolium, monosodium salt) and $20 \mu \mathrm{L}$ of enzyme working solution. The mixture was incubated for $20 \mathrm{~min}$ at $37^{\circ} \mathrm{C}$ and $300 \mathrm{rpm}$ in an orbital shaker, and the absorbance was read at $450 \mathrm{~nm}$. SODs activity was determined by subtracting the sample values to the no-SODs blank. The experiments were carried out three independent times.

\subsection{Determination of cytokine levels and nitric oxide release}

For neuroinflammation assays, BV2 microglial cells were pre-treated with compounds at non-toxic concentrations for $1 \mathrm{~h}$ and activated with $500 \mathrm{ng} / \mathrm{mL}$ LPS for $24 \mathrm{~h}$. All the experiments were carried out as previously described ${ }^{19}$.

The levels of IL-6, TNF- $\alpha$ and IL-10 were evaluated with a ProCartaPlex Multiplex kit (Thermo Fisher Scientific), following manufacturer's instructions. Luminex $200^{\mathrm{TM}}$ instrument and $\mathrm{xPONENT}{ }^{\circledR}$ software (LuminexCorp, Austin, TX) were used to collect the data.

The levels of NO were determined with Griess Reagent Kit, which evaluates the spontaneous oxidation of NO to nitrite under physiological conditions. Cells were cultured in DMEM without phenol red at $1 \times 10^{6}$ cells per well in 12-well plates and treated as described before. Then, $150 \mu \mathrm{L}$ of medium were mixed with $20 \mu \mathrm{L}$ of Griess reagent and $130 \mu \mathrm{L}$ of deionized water. Samples were incubated during $30 \mathrm{~min}$ at room temperature and the absorbance was measured at $548 \mathrm{~nm}$ in a plate reader. All the experiments were performed three times by duplicate.

\subsection{Evaluation of reactive oxygen species levels and glutathione content}

SH-SY5Y and BV2 cells were seeded in 96-well plates at $5 \times 10^{4}$ and $4 \times 10^{4}$ cells per well, respectively. The levels of ROS were analysed with the fluorescent dye carboxy$\mathrm{H}_{2}$ DCFDA (5-(and-6)-carboxy-2', 7'-dichlorodihydrofluorescein diacetate). After treatment with compounds, cells were washed twice with serum-free medium. Then, 20 
$\mu \mathrm{M}$ carboxy- $\mathrm{H}_{2}$ DCFDA dissolved in serum-free medium was added and the plate was incubated in an orbital shaker for $1 \mathrm{~h}$ at $37{ }^{\circ} \mathrm{C}$ and $300 \mathrm{rpm}$. After the incubation, phosphate buffered saline (PBS) was added to each well and the plate was incubated for 30 min at $37^{\circ} \mathrm{C}$ and $300 \mathrm{rpm}$. The fluorescence was read at $527 \mathrm{~nm}$, with an excitation wavelength of $495 \mathrm{~nm}$.

GSH levels were determined with Thiol Tracker ${ }^{\mathrm{TM}}$ Violet dye, following manufacturer's instructions. Cells were rinsed twice with PBS and loaded with the fluorescence dye at $10 \mu \mathrm{M}$ for $30 \mathrm{~min}$ at $37^{\circ} \mathrm{C}$. The resulting fluorescence was read at $404 \mathrm{~nm}$ excitation and $526 \mathrm{~nm}$ emission in a spectrophotometer plate reader. All experiments were carried out three times in triplicate.

\subsection{Protein extraction}

BV2 and SH-SY5Y cells were cultured in 12-well plates at $1 \times 10^{6}$ cells per well and allowed to settle down for $24 \mathrm{~h}$. BV2 cells were pre-treated with compounds for $1 \mathrm{~h}$ and LPS at $500 \mathrm{ng} / \mathrm{mL}$ was added during $24 \mathrm{~h}$. SH-SY5Y cells were treated with the compounds at non-toxic concentrations for $6 \mathrm{~h}$.

Nuclear and cytosolic extraction was performed as previously described ${ }^{19}$. Cells were washed twice with ice-cold PBS and a hypotonic solution was added $(20 \mathrm{mM}$ Tris- $\mathrm{HCl}$ $\mathrm{pH} 7.4,10 \mathrm{mM} \mathrm{NaCl}$ and $3 \mathrm{mM} \mathrm{MgCl}$, containing a phosphatase/protease inhibitors cocktail). Cells were incubated for $15 \mathrm{~min}$ on ice and centrifuged at $3000 \mathrm{rpm}$ and $4{ }^{\circ} \mathrm{C}$ for $15 \mathrm{~min}$. The supernatant was collected as the cytosolic fraction and the protein concentration was quantified with the infrared spectrometer Direct Detect (Merck, Darmstadt, Germany). The pellet was resuspended in a nuclear extraction buffer (100 mM Tris $\mathrm{pH}$ 7.4, $2 \mathrm{mM} \mathrm{Na} \mathrm{VOO}_{4}, 100 \mathrm{mM} \mathrm{NaCl}, 1 \%$ Triton $\mathrm{X}-100,1 \mathrm{mM}$ EDTA, 10\% glycerol, $1 \mathrm{mM}$ EGTA, $0.1 \%$ SDS, $1 \mathrm{mM} \mathrm{NaF}, 0.5 \%$ deoxycholate, and $20 \mathrm{mM} \mathrm{Na} 4 \mathrm{P}_{2} \mathrm{O}_{7}$, 
containing $1 \mathrm{mM}$ PMSF and a protease inhibitor cocktail). Samples were incubated in ice for $30 \mathrm{~min}$, vortexing in intervals of $10 \mathrm{~min}$, and centrifuged at $14000 \mathrm{rpm}$ and $4{ }^{\circ} \mathrm{C}$ for 30 min. The supernatant was saved as the nuclear fraction and quantified by Bradford method.

For the extraction of membranous and cytosolic fractions, cells were lysed with a different buffer $(50 \mathrm{mM}$ Tris $\mathrm{HCl} \mathrm{pH} 7.4,150 \mathrm{mM} \mathrm{NaCl}, 1 \mathrm{mM}$ EDTA and 1\% Triton $\mathrm{x}-100$, supplemented with a complete phosphatase/protease inhibitor cocktail), as previously described ${ }^{37}$. Cells were sonicated and centrifuged at $3000 \mathrm{rpm}$ and $4{ }^{\circ} \mathrm{C}$ for $15 \mathrm{~min}$. The supernatant was collected as cytosolic fraction and the pellet was homogenized in the same lysis buffer. Samples were incubated on ice for $30 \mathrm{~min}$, sonicated in intervals of 10 min, and centrifuged at $12000 \mathrm{rpm}$ and $4{ }^{\circ} \mathrm{C}$ for $30 \mathrm{~min}$. The supernatant obtained was used as the membranous fraction. Protein concentration in both fractions was quantified with Bradford method.

\subsection{Western blot assays}

Samples containing $20 \mu \mathrm{g}$ of cytosolic protein or $10 \mu \mathrm{g}$ of nuclear and membranous protein were loaded in 4-20\% sodium dodecyl sulphate polyacrylamide gels (Biorad, Hercules, CA, USA). Proteins were transferred to PVDF membranes (Merck) with a Trans-Blot ${ }^{\circledR}$ semi-dry transfer cell (Biorad). The Snap i.d. system (Merck) was used for membrane blocking and antibody incubation as previously described ${ }^{19}$. Anti-Nrf2 primary antibody (1:1000, Merck), anti- NFkB-p65 (1:1000, Merck), anti-iNOS antibody (1:5000, Abcam, Cambridge, UK) and anti-gp91-phox (1:1000, Merck) were used to detect their corresponding proteins. Protein band intensity was corrected using anti- lamin B1 (1:5000, Abcam), anti-sodium potassium ATPase (1:10000, Abcam), anti- $\beta$-actin (1:10000, Merck) and anti-GAPDH (1:5000, Merck) in nuclear, membranous, and 
cytosolic fractions, respectively. The immunoreactive bands were detected with Supersignal West Pico Luminiscent Substrate and Supersignal West Femto Maximum Sensitivity Substrate. Diversity GeneSnap system and software (Syngene, Cambridge, U.K.) were used for protein bands detection. Experiments were performed at least three independent times by duplicate.

\subsection{Trans-well co-culture}

SH-SY5Y cells were seeded in 24-well plates at 5x10 5 cells per well and BV2 microglial cells were seeded in culture inserts $(0.4 \mu \mathrm{M}$ pore size, Merck) placed above neuroblastoma cells at $2.5 \times 10^{5}$ cells per well. Cells were allowed to grow for $24 \mathrm{~h}$ and microglial cells were treated with compounds at selected concentrations for $1 \mathrm{~h}$ and 500 $\mathrm{ng} / \mathrm{mL}$ LPS for $24 \mathrm{~h}$. After the incubation, the cell viability of SH-SY5Y cells was assessed with MTT assay as described above ${ }^{19}$.

\subsection{Statistical analysis}

Data are presented as mean \pm SEM. Differences were evaluated by one-way ANOVA and Dunnett's post hoc test with Graph Pad Prism 8.0 software. Statistical significance was considered at $* p<0.05, * * p<0.01$ and $* * * p<0.001$.

\section{AUTHOR INFORMATION}

\section{Corresponding Author}

*Email: luis.botana@usc.es. Phone/Fax: +34982822233.

\section{Author Contributions}

R.A. and N.P performed in vitro experiments. J.N.T. isolated and characterized the compounds. E.A, A.A and L.M.B. did critical discussion and experimental design. The manuscript was written with the contributions of all authors. 


\section{Conflict of interest}

The authors have no conflicts of interest to declare

\section{Acknowledgments}

The research leading to these results has received funding from the following FEDER cofunded-grants. From Consellería de Cultura, Educación e Ordenación Universitaria, Xunta de Galicia, 2017 GRC GI-1682 (ED431C 2017/01). From Ministerio de Ciencia e Innovación IISCIII/PI19/001248. From European Union Interreg AlertoxNet EAPA-3172016, Interreg Agritox EAPA-998-2018, and H2020 778069-EMERTOX. JT wishes to thank Marcel Jaspars of Marine Biodiscovery Centre, University of Aberdeen for financial support under European Union's Seventh Framework Programme (FP7/20172013) under grant agreement no. 312184 "PharmaSea", and Klaus Feussner of the University of the South Pacific, Fiji Islands, for sample collections. 


\section{References}

1. Alzheimer's-Association, 2016 Alzheimer's disease facts and figures. Alzheimer's \& dementia : the journal of the Alzheimer's Association 2016, 12 (4), 459-509.

2. Cahill, S., WHO's global action plan on the public health response to dementia: some challenges and opportunities. Aging Ment Health 2020, 24 (2), 197-199.

3. Cobley, J. N.; Fiorello, M. L.; Bailey, D. M., 13 reasons why the brain is susceptible to oxidative stress. Redox Biol 2018, 15, 490-503.

4. Perez Ortiz, J. M.; Swerdlow, R. H., Mitochondrial dysfunction in Alzheimer's disease: Role in pathogenesis and novel therapeutic opportunities. Br J Pharmacol 2019, 176 (18), 3489-3507.

5. Panel, M.; Ghaleh, B.; Morin, D., Mitochondria and aging: A role for the mitochondrial transition pore? Aging Cell 2018, 17 (4), e12793.

6. Rojo, A. I.; McBean, G.; Cindric, M.; Egea, J.; Lopez, M. G.; Rada, P.; Zarkovic, N.; Cuadrado, A., Redox control of microglial function: molecular mechanisms and functional significance. Antioxidants \& redox signaling 2014, 21 (12), 1766-801.

7. Scheiblich, H.; Trombly, M.; Ramirez, A.; Heneka, M. T., Neuroimmune Connections in Aging and Neurodegenerative Diseases. Trends Immunol 2020, 41 (4), 300-312.

8. Jin, X.; Liu, M. Y.; Zhang, D. F.; Zhong, X.; Du, K.; Qian, P.; Gao, H.; Wei, M. J., Natural products as a potential modulator of microglial polarization in neurodegenerative diseases. Pharmacol Res 2019, 145, 104253.

9. Liang, X.; Luo, D.; Luesch, H., Advances in Exploring the Therapeutic Potential of Marine Natural Products. Pharmacol Res 2019, 147, 104373.

10. Feussner, K. D.; Ragini, K.; Kumar, R.; Soapi, K. M.; Aalbersberg, W. G.; Harper, M. K.; Carte, B.; Ireland, C. M., Investigations of the marine flora and fauna of the Fiji Islands. Nat Prod Rep 2012, 29 (12), 1424-62.

11. Tabudravu, J. N.; Pellissier, L.; Smith, A. J.; Subko, K.; Autreau, C.; Feussner, K.; Hardy, D.; Butler, D.; Kidd, R.; Milton, E. J., et al., LC-HRMS-Database Screening Metrics for Rapid Prioritization of Samples to Accelerate the Discovery of Structurally New Natural Products. J Nat Prod 2019, 82 (2), 211-220.

12. Tabudravu, J. N.; Morris, L. A.; Milne, B. F.; Jaspars, M., Conformational studies of free and $\mathrm{Li}+$ complexed jasplakinolide, a cyclic depsipeptide from the Fijian marine sponge Jaspis splendens. Org Biomol Chem 2005, 3 (5), 745-9.

13. Holzinger, A., Jasplakinolide: an actin-specific reagent that promotes actin polymerization. Methods $\mathrm{Mol}$ Biol 2009, 586, 71-87.

14. Ghosh, A. K.; Dawson, Z. L.; Moon, D. K.; Bai, R.; Hamel, E., Synthesis and biological evaluation of new jasplakinolide (jaspamide) analogs. Bioorg Med Chem Lett 2010, 20 (17), 5104-7.

15. Andavan, G. S.; Lemmens-Gruber, R., Cyclodepsipeptides from marine sponges: natural agents for drug research. Mar Drugs 2010, 8 (3), 810-34.

16. Alvariño, R.; Alonso, E.; Tribalat, M. A.; Gegunde, S.; Thomas, O. P.; Botana, L. M., Evaluation of the Protective Effects of Sarains on H2O2-Induced Mitochondrial Dysfunction and Oxidative Stress in SH-SY5Y Neuroblastoma Cells. Neurotoxicity research 2017, 32 (3), 368380.

17. Angelova, P. R.; Abramov, A. Y., Role of mitochondrial ROS in the brain: from physiology to neurodegeneration. FEBS letters 2018, 592 (5), 692-702.

18. Dinkova-Kostova, A. T.; Kostov, R. V.; Kazantsev, A. G., The role of Nrf2 signaling in counteracting neurodegenerative diseases. Febs $j$ 2018, 285 (19), 3576-3590.

19. Alvariño, R.; Alonso, E.; Lacret, R.; Oves-Costales, D.; Genilloud, O.; Reyes, F.; Alfonso, A.; Botana, L. M., Caniferolide A, a Macrolide from Streptomyces caniferus, Attenuates 
Neuroinflammation, Oxidative Stress, Amyloid-Beta, and Tau Pathology in Vitro. Mol Pharm 2019, 16 (4), 1456-1466.

20. Haslund-Vinding, J.; McBean, G.; Jaquet, V.; Vilhardt, F., NADPH oxidases in oxidant production by microglia: activating receptors, pharmacology and association with disease. $\mathrm{Br} J$ Pharmacol 2017, 174 (12), 1733-1749.

21. Thawkar, B. S.; Kaur, G., Inhibitors of NF-kappaB and P2X7/NLRP3/Caspase 1 pathway in microglia: Novel therapeutic opportunities in neuroinflammation induced early-stage Alzheimer's disease. J Neuroimmunol 2019, 326, 62-74.

22. Bahn, G.; Jo, D. G., Therapeutic Approaches to Alzheimer's Disease Through Modulation of NRF2. Neuromolecular Med 2019, 21 (1), 1-11.

23. Wang, Y.; Yan, T.; Lu, H.; Yin, W.; Lin, B.; Fan, W.; Zhang, X.; Fernandez-Funez, P., Lessons from Anti-Amyloid-beta Immunotherapies in Alzheimer Disease: Aiming at a Moving Target. Neurodegener Dis 2017, 17 (6), 242-250.

24. Teil, M.; Arotcarena, M. L.; Faggiani, E.; Laferriere, F.; Bezard, E.; Dehay, B., Targeting alpha-synuclein for PD Therapeutics: A Pursuit on All Fronts. Biomolecules 2020, 10 (3), 391.

25. Cabral-Costa, J. V.; Kowaltowski, A. J., Neurological disorders and mitochondria. Mol Aspects Med 2020, 71, 100826.

26. Tejera, D.; Heneka, M. T., Microglia in Neurodegenerative Disorders. Methods Mol Biol 2019, 2034, 57-67.

27. Habtemariam, S., Natural Products in Alzheimer's Disease Therapy: Would Old Therapeutic Approaches Fix the Broken Promise of Modern Medicines? Molecules 2019, 24 (8), 1519.

28. Ghosh, S.; Castillo, E.; Frias, E. S.; Swanson, R. A., Bioenergetic regulation of microglia. Glia 2018, 66 (6), 1200-1212.

29. Cinelli, M. A.; Do, H. T.; Miley, G. P.; Silverman, R. B., Inducible nitric oxide synthase: Regulation, structure, and inhibition. Med Res Rev 2020, 40 (1), 158-189.

30. Simpson, D. S. A.; Oliver, P. L., ROS Generation in Microglia: Understanding Oxidative Stress and Inflammation in Neurodegenerative Disease. Antioxidants (Basel) 2020, 9 (8), 743. 31. Quinti, L.; Dayalan Naidu, S.; Träger, U.; Chen, X.; Kegel-Gleason, K.; Llères, D.; Connolly, C.; Chopra, V.; Low, C.; Moniot, S., et al., KEAP1-modifying small molecule reveals muted NRF2 signaling responses in neural stem cells from Huntington's disease patients. In Proc Natl Acad Sci U S A, 2017; Vol. 114, pp E4676-85.

32. Sivandzade, F.; Prasad, S.; Bhalerao, A.; Cucullo, L., NRF2 and NF-қB interplay in cerebrovascular and neurodegenerative disorders: Molecular mechanisms and possible therapeutic approaches. Redox Biol 2019, 21, 101059.

33. Porro, C.; Cianciulli, A.; Panaro, M. A., The Regulatory Role of IL-10 in Neurodegenerative Diseases. Biomolecules 2020, 10 (7), 1017.

34. Uddin, M. S.; Al Mamun, A.; Kabir, M. T.; Ahmad, J.; Jeandet, P.; Sarwar, M. S.; Ashraf, G. M.; Aleya, L., Neuroprotective role of polyphenols against oxidative stress-mediated neurodegeneration. Eur J Pharmacol 2020, 886, 173412.

35. Chirumbolo, S., The role of quercetin, flavonols and flavones in modulating inflammatory cell function. Inflamm Allergy Drug Targets 2010, 9 (4), 263-85.

36. Jodynis-Liebert, J.; Kujawska, M., Biphasic Dose-Response Induced by Phytochemicals: Experimental Evidence. J Clin Med 2020, 9 (3), 718.

37. Alonso, E.; Vale, C.; Vieytes, M. R.; Botana, L. M., Translocation of PKC by yessotoxin in an in vitro model of Alzheimer's disease with improvement of tau and beta-amyloid pathology. ACS Chem Neurosci 2013, 4 (7), 1062-70. 
For Table of contents only

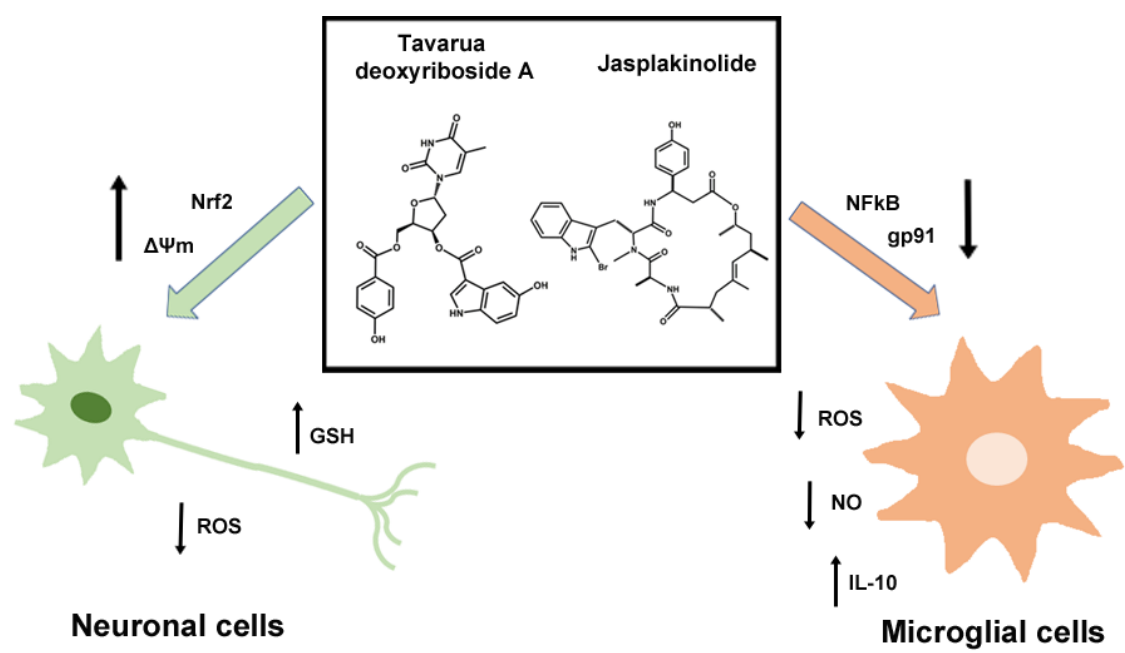

